\title{
PENERAPAN AQUAPONIK DAN PENGEMBANGAN BUDIDAYA IKAN LELE PADA UNIT USAHA PONDOK PESANTREN KOTA MALANG
}

\section{(APPLICATION OF AQUAPONIC AND CATFISH CULTIVATION DEVELOPMENT IN ISLAMIC BOARDING BUSINESS UNIT MALANG CITY)}

\author{
Abdul Halim ${ }^{1}$, Suslam Pratamaningtyas ${ }^{2}$ \\ ${ }^{1,2}$ Jurusan Teknik Sipil, Universitas Widyagama, Malang \\ e-mail: abah.ef7@gmail.com
}

\begin{abstract}
Tarbiyatul Iman Islamic Boarding School (PPTI) located on Jalan Perum Srigading Dalam Kav 11 Malang has a catfish breeding business under the name "Catfish PPTI". The catfish farmers group is a partner in the community partnership program (PKM). The partner group is hoping for good management of fish culture production. The appropriate technology is technology in cultivating fish with a "Bionic" system that combines organic fish farming with organic vegetable plants in limited lands, with the intention of feeding and place efficiency and operational costs. The implementation of PKM in Tarbiyatul Iman Islamic Boarding School (PPTI) begins with coordination with the management. PPTI already has 2 catfish ponds which have been managed as they are as learning media for students. With the existence of this PKM, the number of ponds owned by PPTI has become 7 ponds, plus the installation of aquaponics with a pot system and pipes. There are two aquaponic system models implemented in PPTI, namely the first model where vegetables are grown in pots filled with planting media consisting of gravel / zeolite and husks. Pond water is channeled into plant pots which are arranged on top of a pool and flows out into the pond. While the second model is pond water flowed into PVC pipes, where the pipes are perforated and filled with plants that have been planted in a net pot and the water will be re-inserted into the fish pond.
\end{abstract}

Kerywords: $\mathrm{CaO}$, Cement, Lapindo mud, Mortar Geopolymer

\begin{abstract}
abstrak
Pondok Pesantren Tarbiyatul Iman (PPTI) yang berlokasi di Jalan Perum Srigading Dalam Kav 11 Malang mempunyai unit usaha budidya ikan lele dengan nama "Lele PPTI". Kelompok pembudidaya ikan lele ini merupakan mitra program kemitraan masyarakat (PKM). Kelompok mitra mengharapkan manajemen produksi budidaya ikan yang baik. Teknologi tepat guna tersebut adalah teknologi membudidayakan ikan dengan sistem" Bionic" yaitu menggabungkan budidaya ikan secara organik dengan tanaman sayur organik di lahan terbatas, dengan maksud efisiensi pakan, tempat, serta biaya operasional. Pelaksanaan PKM di Pondok Pesantren Tarbiyatul Iman (PPTI) diawali koordinasi dengan para pengurus. PPTI sudah memiliki 2 buah kolam ikan lele yang selama ini dikelola apa adanya sebagai media pembelajaran bagi santri. Dengan adanya PKM ini, jumlah kolam yang dimiliki PPTI menjadi 7 buah kolam, ditambah dengan instalasi aquaponik sistem pot dan pipa. Ada dua model system aquaponik yang diterapkan, yaitu pertama dimana sayuran ditanam dalam pot yang diisi media tanam yang terdiri dari batu kerikil/zeolite dan sekam. Air kolam dialirkan ke pot-pot tanaman yang disusun di atas kolam ikan dan mengalir keluar kembali masuk ke kolam. Model kedua adalah air kolam dialirkan ke dalam pipa-pipa PVC, pipa-pipa tersebut dilubangi dan diisi tanaman yang telah disemaikan pada net pot dan air akan kembali dimasukkan ke dalam kolam ikan.
\end{abstract}

Kata kunci: $\mathrm{CaO}$, Lumpur lapindo, Mortar Geopolimer, Semen 


\section{PENDAHULUAN}

Pondok Pesantren Tarbiyatul Iman (PPTI) bertempat di perumahan srigading kav. 0912, RT 3, RW 2, tembalangan, kelurahan jatimulyo, kecamatan lowokwaru, kota malang, provinsi Jawa Timur. PPTI didirikan pada tanggal 20 Januari tahun 2011. PPTI merupakan salah satu lembaga pendidikan yang bernaung di bawah Lembaga Pendidikan Putera Zaman (LPPZ) yang membentuk program pendidikan berbasis pesantren. Untuk mendukung visi dan misinya PPTI memiliki progam unggulan yaitu menerjemahkan Al-Qur'an dan membaca kitab klasik (kitab kuning). Selain progam pendidikan kepesantrenan PPTI juga berusaha mengajarkan kepada santri, tentang tugas manusia di bumi antara lain sebagai seorang pengelola bumi (khalifah) untuk menjaga, merawat dan memakmurkan bumi Allah Subhanallahu Wa Ta'ala, oleh karena PPTI berusaha mengajarkan peran tersebut dengan membuat ekstrakulikuler bernuansa alam, yaitu ekstakulikuler belajar iman dari menanam dan budidaya ikan. Ekstrakulikuler ini mengajarkan kepada para santri bagaimana menanam dan berternak yang baik dan benar sekaligus menanamkan nilai-nilai iman kepada Allah Subhanallahu Wa Ta'ala dalam setiap proses pembelajaranya.

Salah satu media ekstrakulikuler budidaya ikan adalah unit usaha pondok dalam budidaya ikan lele, yang hasil budidaya tersebut masih sebatas konsumsi santri dan dijual pada penduduk disekitar pondok. Beberapa permasalahan yang dihadapi Unit Usaha PPTI sebagai mitra dalam kegiatan Pengabdian Masyarakat adalah antara lain 1) dari segi produksi meliputi keterbatasan lahan, terciumnya bau dari air kolam ikan, setelah panen air dibuang begitu saja namun mengandung nutrisi yang dapat berfungsi sebagai pupuk, Diperlukan 2,5 - $3 \mathrm{~m}^{3}$ air untuk memulai budidaya ikan lele lagi, tidak ada instalasi untuk pembuangan air kotor bekas budidaya. Sedangkan dari aspek manajemen mitra belum memahami manajemen produksi budidaya ikan dan manajemen keuangan, bagaimana cara pembukuan yang baik, belum paham bagaimana cara menganalisa kelayakan ekonomi dan kelayakan keuangan dalam usaha budidaya ikan lele.

\section{METODE PENGABDIAN MASYARAKAT}

Skala prioritas yang diambil berdasarkan beberapa kali diskusi sehingga didapat kesepakat dengan mitra untuk mengatasi permasalahannya adalah sebagai berikut:

Agar didapat kelayakan ekonomis perlu menambah kolam ikan. Diharapkan penambahan jumlah kolam ikan akan menjadikan pemakaian aerator akan lebih optimal dan tenaga kerja akan lebih hemat. Selain itu diberikan pelatihan manajemen produksi dan pasca produksi.

Untuk mengatasi bau air kolam tetapikandungan nutrisi dari sisa makanan dan kotoran ikan tetap dapat digunakan, maka diperlukan perbaikan manajemen kualitas air dengan cara menggunakan Sistem Bionic (bio natural and aquaponic combination). Sistem ini dikenal dengan nama Aquaponik yaitu suatu system budidaya Natural yang digabungkan dengan tanaman tanaman organik yang memanfaatkan air limbah budidaya. 
Melaksanakan pelatihan manajemen keuangan, agar mitra dapat melakukan pembukuan dengan baik dan dapat menganalisa kelayakan ekonomi dan kelayakan keuangan dari usaha budidaya ikan lele.

\section{HASIL DAN PEMBAHASAN}

Kegiatan pertama kali yang dilakukan oleh Tim PKM adalah melakukan diskusi dengan para pengasuh pondok untuk mengetahui lebih jelas permasalahan yang dihadapi dan mendiskusikan rencana untuk mengatasi masalah yang dihadapi oleh mitra dalam hal ini pondok Pesantren Tarbiyatul Iman Malang. Dicapai kesepakatan adalah memindahkan lokasi kolam yang ada sehingga tahap awal yang dikerjakan adalah menyiapkan lahan baru buat kolam ikan. Karena kontur tanah lokasi kolam ikan ketinggian permukaan tanah tidak sama, maka dipasang dinding penahan dari batu bata. Pada lokasi yang baru dibangun juga saluran pembuangan dari pipa PVC 2,5 dim yang dilengkapi dengan stop kran.
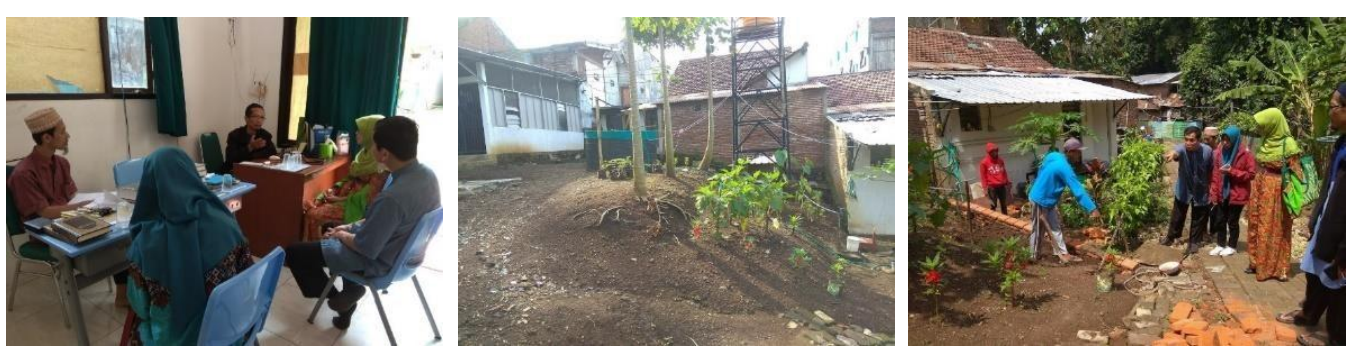

Gambar 1. Diskusi dengan pengasuh PPTI, Kondisi eksisting lahan baru kolam ikan PPTI, dan pemasangan dinding penahan dari batu bata,

Pembuatan media budidaya ikan dan sayuran dengan system aquaponik. Alasan mengapa dipilih system aquaponik karena Nutrisi kimia cair digantikan dengan nutrisi yang dikandung didalam air kolam yang berasal dari kotoran ikan dan sisa makanan ikan, menjadikan kualitas air kolam lebih baik, produktivitas sayuran lebih baik dibandingkan dengan system hidroponik.

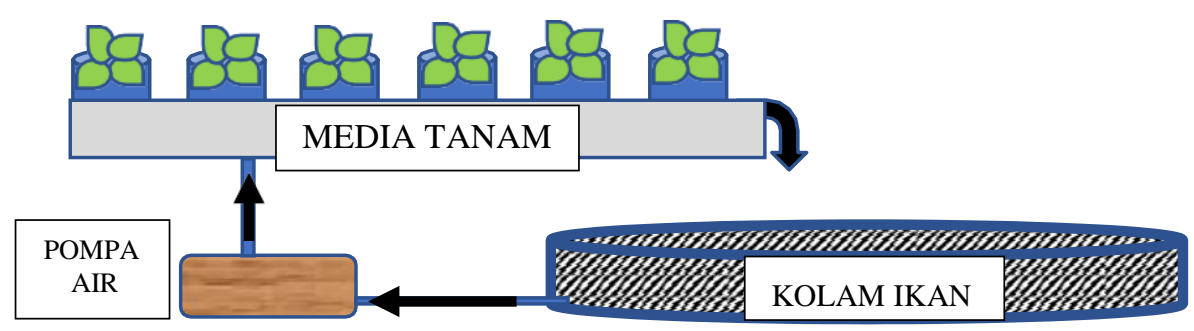

Gambar 2. Prinsip Kerja Aquaponik 
Gambar 2 menunjukkan bagaimana prinsip kerja aguaponik. Senyawa amoniak didalam kolam diuraikan oleh probiotik menjadi nutrisi nitrat dipompakan ke media tanam. Nutrisi diserap akar tanaman dan akar tanaman mengerluarkan oksigen masuk ke dalam air. Setelah itu air dialirkan kembali ke kolam ikan. Gambar 2 juga menunjukkan Komponen Utama dari Aquaponik berupa: 1) Kolam Ikan (akuakultur); 2) Media Tanam (hidroponik); 3) Saluran penghubung (perpipaan dan pompa)

Kolam ikan yang digunakan adalah kolam berbentuk bulat dengan bahan dari terpal yang disebut dengan kolam terpal bioflok. Kenapa dipilih system bioflok karena ada beberapa keuntungan, antara lain : 1) Pemakaian air lebih hemat; 2) Pemberian pakan lele lebih hemat; 3) Pengisian ikan lebih banyak; 4) Pertumbuhan ikan yang baik dan seragam; 5) Panen ikan lebih memuaskan.

Alat-alat yang dibutuhkan : 1) Terpal khusus kolam bulat dan Terpal talang; 2) Besi wire-mesh, diameter $6 \mathrm{~mm}$, Panjang 6,4 $\mathrm{m}$ dan lebar 2,1 m. untuk rangka kola; 3) Pipa PVC diameter 2 “, Tutup pipa (dop) 2 “, Stop kran 2 “, Cable ties; 4) Gergaji besi, Bor, Gerinda dan Las listrik, Aerator, Selang

Langkah-Langkah : 1) Potong wiremesh menjadi dua bagian sama panjang menjadi 105 $\mathrm{cm}$. Bisa menjadi 2 kolam; 2) Hubungkan kedua ujung wiremesh sehingga berbentuk lingkaran, ikat kedua ujungnya dengan kabel ties. (sebagai rangka kolam); 3) Gerinda bagian ujung wire mesh yang tajam; 4) Siapkan lokasi kolam, ratakan tanahnya usahakan berbentuk kerucut dengan bagian tengah elevasinya lebih rendah; 5) Gali tanah buat menanam pipa pembuangan; 6) Letakkan rangka di lokasi kolam; 7) Pasang karpet talang pada bagian dalam rangka dan diikat dengan kabel ties; 8) Pasangkan terpal hingga terbentuk kolam bulat yang rapi, ikat dengan bendrat atau kabel ties; 9) Buat pipa saluran pembuangan berdiameter 2 " yang terdiri dari pipa tegak $30 \mathrm{~cm}$ diberi lobang disekeliling pipa, pipa tegak $90 \mathrm{~cm}$, pipa horizontal $110 \mathrm{~cm}$, Stop kran, knee dan $\mathrm{T}$; 10) Lubangi bagian tengah kolam masukkan pipa tegak $30 \mathrm{~cm}$ saluran pembuangan dan pipa tegak $90 \mathrm{~cm}$ dan stop kran berada diluar kolam.
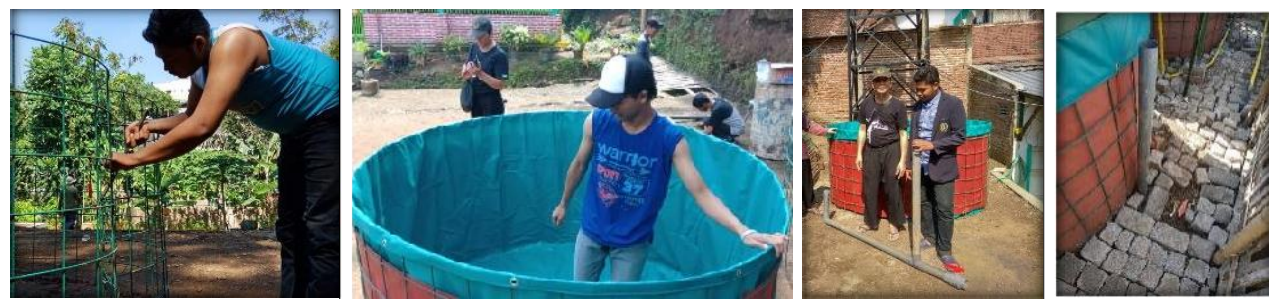

Gambar 3. Pemasangan Kolam Terpal Bulat (a) Menghubungkan ke dua ujung rangka besi wire mesh sehingga berbentuk lingkaran dan diikat dengan kabel ties. (b)

Memasang Terpal (c) Menyiapkan pipa pembuangan (d) Pipa pembuangan

Pengisian Air dan Penyebaran Benih Ikan Lele dengan langkah-langkah berikut: 1) Bersihkan dulu sisi dalam kolam dari bekas lem atau zat-zat kimia yang menempel; 2) Isi kolam setinggi 20 - $40 \mathrm{~cm}$ diberi campuran $200 \mathrm{ml}$ molase (tetes), $9 \mathrm{~kg}$ garam dan $250 \mathrm{ml}$ probiotik dan 5 liter air yang telah diaduk rata; 3) Diamkan selama $3-7$ hari 
agar muncul lumut-lumut didinding kolam dan perkembangan fito plankton; 4) Masukkan benih ikan lele, dengan cara masukkan kantong plastik yang berisi benih ke dalam kolam, buka ikatan kantong plastic, biarkan air kolam masuk ke dalam kantong plastik, biarkan ikan beradaptasi dengan air kolam dan keluar sendiri dari kantong plastic, Benih jangan dipaksa keluar kantong dengan mengangkat kantong plastik tersebut; 5) Seiring dengan pertumbuhan ikan, air kolam ditambah sampai ketinggian $80 \mathrm{~cm}$.
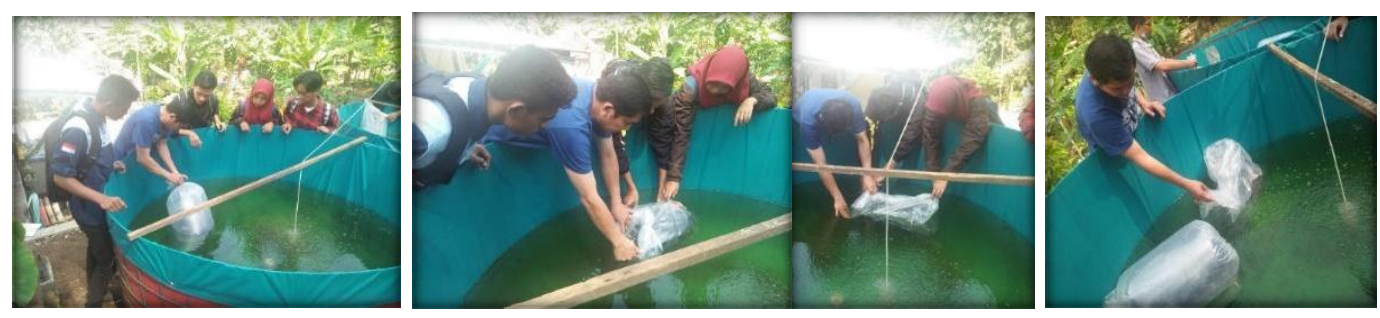

Gambar 4. Penyebaran Benih

Pembuatan media tanam pada sistem hidroponik yang telah dibuat adalah gabungan antara system mengapung/menggenang dan system mengalir. Bahan yang diperlukan adalah sebagai berikut: 1) Kayu atau Gavalum $C$ atau pipa air 3/4 dim, yag digunakan sebagai rangka untuk meletakkan pipa-pipa hidroponik; Untuk mendapatkan 1 buah rangka penyangga pipa, potong -potong gavalum panjang $190 \mathrm{~cm}$ sebanyak 2 buah (untuk kaki rangka), panjang $80 \mathrm{~cm}$ sebanyak 1 buah sebagai pengaku bawah seakligus penyangga pipa bagian bawah, $20 \mathrm{~cm}$ sebanyak 8 buah untuk penyangga pipa; 2) Buat 3 buah rangka, masing-masing dipasang 2 buah diujung dan 1 ditengahtengah. Hubungkan ketiga rangka tersebut dengan pengaku dari gavalum dengan panjang 3,75 m dipasang 1 atas dan 2 di bawah; 3) Pipa diameter 2,5 " type AW minimal type D sebanyak 10 lonjor (atau sesuai kebutuhan); 4) Lobangi pipa dengan diameter $5 \mathrm{~cm}$ dengan jarak $15 \mathrm{~cm}$ antar as setiap lobang. Untuk 1 lonjor pipa akan mendapatkan 26 lobang; 5) Kedua ujung pipa ditutup dengan dop pipa diameter 2,5 “. (ujung A dan B); 6) Dop ujung pipa A pada bagian bawah dilobangi dengan diameter $1 / 2$ " sebagai inlet air masuk; 7) Dop ujung pipa B kira setinggi 2-3 cm dari bawah dilobangi dengan diameter; 8) $1 / 2$ " sebagai oulet air keluar, sehingga didalam pipa akan terjadi genangan air; 9) Taruh pipa-pipa yang telah diberi lobang ke atas rangka gavalum. Hubungkan masing-masing dop yang telah diberi lobang dengan selang berdiameter $1 / 2$ ". 

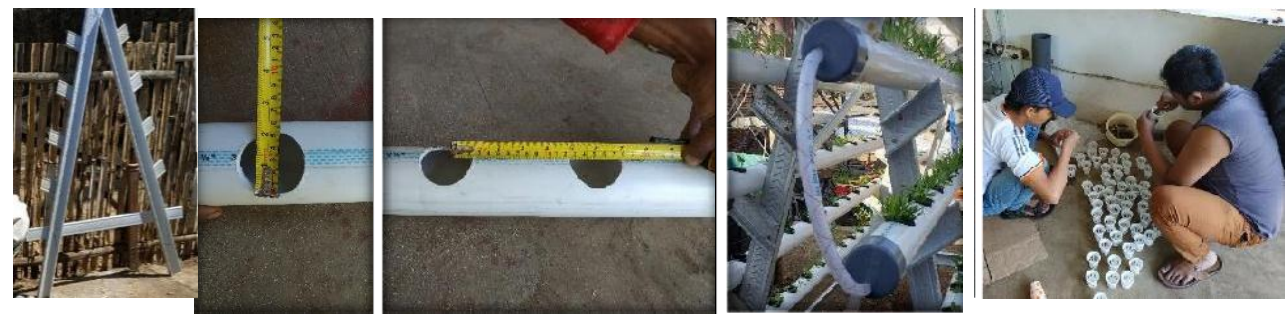

Gambar 5. Membuat Media Budidaya sayuran (Hidroponik) dari Rangka Gavalum dan pipa diameter 2 “.

Dari kegiatan PKM ini santri sudah memanen beberapa kali kangkung dan sayuran lainnya yang ditanam dengan sistem aquaponik, hasil panen dimanfaatkan oleh PPTI untuk konsumsi sendiri para santri, sedangkan untuk budidaya ikan sudah dilakukan pemanenan secara bertahap untuk keperluan konsumsi santri maupun dibeli para pelanggan dengan harga Rp. 16.500/kg.

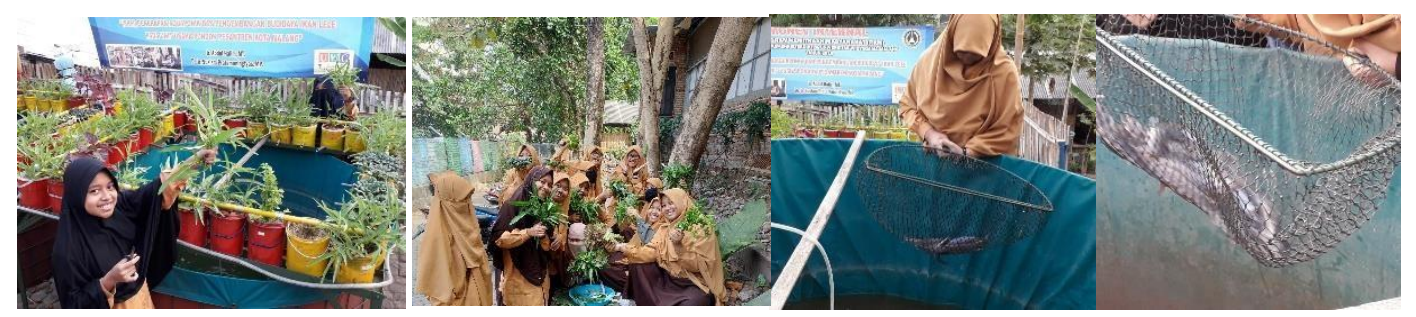

Gambar 6. Santri PPTI Panen Kangkung dan sayuran lainnya serta panen ikan lele

Permasalahan dari aquaponik sistem pipa adalah air yang bercampur dengan kotoran ikan dan lumut tertahan di akar-akar kangkung mengakibatkan aliran air tidak lancar dan muncul jentik-jentik nyamuk. Permasalahan ini diatasi dengan menurunkan lobang selang untuk keluar air agar air keluar semua tanpa adanya genangan. Permasalahan pada budidaya ikan adalah pemasaran yang masih terkendala.

\section{PENUTUP}

\section{Simpulan dan Saran}

Pelaksanaan kegiatan PKM di Pondok Pesantren Tarbiyatul Iman dalam upaya meningkatkan dan mengembangkan unit usaha budidaya ikan lele berjalan dengan baik. Pembuatan aquaponik berupa 5 kolam ikan dan 2 model budidaya sayuran sudah dilaksanakan dan diserahkan kepada pihak Pondok Pesantren Tarbiyatul Iman Malang. Hasil budidaya sayuran dan budidaya ikan lele dengan menggunakan sistem aquaponik sudah dinikmati oleh pihak pondok, masyarakat disekitar pondok dan pelanggan /pembeli ikan lele. Pendampingan masih diperlukan untuk mengatasi permasalahan-permasalahan yang dihadapi pihak pondok dalam menjalankan unit usahanya. 


\section{DAFTAR PUSTAKA}

Admin (2018). Pengertian Aquaponik, Terssedia pada : Https://Edukanal.Com/Pengertian-Aquaponik-Dan-Manfaatnya/ (1 September 2018)

Forum Hidroponik. (2016). Cara Membuat Akuaponik Sederhana (Akuaponik Rakit Apung), Tersedia pada : http://www.kebunpedia.com/threads/cara-membuatakuaponik-sederhana-akuaponik-rakit-apung.5904/ (28 Agustus 2018)

Meblogerbank (2017). Akuaponik, Biofilter dan Pupuknya, Tersedia pada : https://meblogerbank.wordpress.com/2017/06/20/akuaponik-biofilter-danpupuk- nya/ (1 September 2018) 